Perkembangan Lagu Indonesia Raya (Tahun 1928-2009) | Febriansyah Pratama Putra, Fajriudin, Agus Permana

\title{
Perkembangan Lagu Indonesia Raya (Tahun 1928-2009)
}

\author{
Febriansyah Pratama Putra, Fajriudin, Agus Permana \\ Fakultas Adab dan Humaniora \\ Universitas Islam Negeri Sunan Gunung Djati Bandung \\ email: ferbryanmiddleton97@gmail.com
}

\begin{abstract}
The Indonesia Raya song is the National Anthem of the Republic of Indonesia, which was created by Wage Rudolf Supratman and is the only song among his many songs that is used as the national anthem. This song was first introduced to the public on October 28,1928 as a struggle song to unite the nation. The meaning contained in the lyrics of the song is very deep and the melody is made very lively when the song is played. In its development, this song was also sung on various occasions, including when birthdays or weddings with different versions. This happens because there is no mutual agreement in the lyrics and arrangements of the song Indonesia Raya. For this reason, it is necessary to conduct research on the development of the Indonesia Raya Song from 1928 to 2009.
\end{abstract}

Keywords: Indonesia Raya song, Policy. 
Perkembangan Lagu Indonesia Raya (Tahun 1928-2009) | Febriansyah Pratama Putra, Fajriudin, Agus Permana

\section{Pendahuluan}

Sebuah lagu kebangsaan dimulai dari lagu perjuangan yang telah memenuhi beberapa kriteria yang berasal dari undang-undang konstitusi pemerintah. Hal tersebut terdapat dalam Lagu Kebangsaan Indonesia Raya yang telah memenuhi kriteria tersebut. Dalam lagu tersebut juga terdapat nilai estetisnya, dimaksudkan secara seremonial tidak selalu harus memenuhi persyaratan teknik komposisi musik yang sempurna seperti karya musik simponi. Beberapa ahli mengatakan bahwa lemahnya lagu kebangsaan tidak hanya ditinjau dari komposisi musik, tetapi juga daya tariknya yang mampu membangkitkan semangat terutama makna yang terkandung dalam syair lagu itu ${ }^{1}$.

Pada awalnya pertama kali dikumandangkan Lagu Indonesia Raya berjumlah 81 birama dengan menggunakan irama wals ${ }^{2}$ 6/8. Akan tetapi, irama wals tersebut menyebabkan lagu ini tidak memiliki tekanan yang senada dalam tekanan pada mars. Selain itu, lagu ini pada dasarnya memiliki aksen yang datar serta tempo yang sangat lambat iringan musiknya dengan tangga nada $\mathrm{C}$ natural sesuai register instrumen biola dan belum memperhitungkan ambitus suara vokal manusia. Kebanyakan musik memiliki jumlah ketukan yang banyaknya pada setiap biramanya.

Lagu Indonesia Raya memiliki wals yang dihitung 3 ketukan (Triple) atau sukat yang tersusun dalam 6 ketukan dalam satu birama. Wals tersebut menyebabkan lagu ini terasa lebih berat karena jumlah ketukannya yang terlalu banyak ${ }^{3}$. Lagu Indonesia mengalami pasang surut pada kedudukan pemerintah Jepang. Pada tahun 1944 dibentuk panitia lagu kebangsaan yang dipimpin oleh Sukarno dengan anggota Ki Hadjar Dewantara, Achyar, Bintang Sudibyo, Darma Wijaya, Kusbini, KH. Masyur, Mr. Muhammad Yamin, Mr. Sastro Moelyono, Sanusi Pane, Cornel Simandjuntak, Mr. Achmad Soebardjo, dan Utoyo. Lagu Indonesia disahkan pada tahun 1944, lagu tersebut dikumandangkan pada rapat pertemuan dan upacara tertentu.

Lagu Kebangsaan Indonesia Raya dinyanyikan dalam beberapa versi dengan ketukan, irama dan gubahan yang berbeda-beda. Lagu ini juga dapat

${ }^{1}$ Mintargo Wisnu, "KONTINUITAS DAN PERUBAHAN MAKNA LAGU KEBANGSAAN INDONESIA RAYA," Kawistara: Jurnal Ilmiah Sosial Dan Humaniora 2, no. 3 (2012): 309, https://jurnal.ugm.ac.id/kawistara/article/view/3942.

${ }^{2}$ Wals atau dikenal juga dengan birama merupakan tanda yang menerangkan banyaknya ketukan pada setiap bar untuk menentukan nilai ketukan.

3 Wisnu, "KONTINUITAS DAN PERUBAHAN MAKNA LAGU KEBANGSAAN INDONESIA RAYA,” 301. 
dinyanyikan dalam berbagai kesempatan, diantaranya ketika acara ulang tahun ataupun acara pernikahan. Hal tersebut terjadi karena belum ada peraturan pasti dan baku tentang Lagu Indonesia Raya. Pemerintah mengeluarkan peraturan no. 44 pada tahun 1958 tentang Lagu Kebangsaan Indonesia Raya sebagai sebuah respon terhadap lagu kebangsaan pada tahuntahun sebelumnya. Peraturan Pemerintah no. 44 tahun 1958 memuat tentang seluruh aspek lagu kebangsaan.

\section{Metode Penelitian}

Dalam melakukan penelitian ini, dengan menggunakan metode penelitian sejarah yaitu penelitian mempelajari kejadian-kejadian atau peristiwa-peristiwa di masa lampau dengan tujuan untuk membuat rekontruksi masa lampau secara sistematis dan secara objektif dengan cara mengumpulkan, mengevaluasi, memverifikasi, serta mensistematikan buktibukti untuk menegakan fakta dan memperoleh kesimpulan yang kuat, dengan cara melalui empat cara yaitu:

\section{Heuristik}

Sumber-sumber sejarah yang dibutuhkan dalam penulisan proposal penelitian ini dikumpulkan berdasarkan bahan-bahan yang ada relevansi dengan tema yang penulis pilih. Heuristik merupakan suatu keterampilan dalam menemukan, menangani, dan memperinci atau mengklasifikasikan catatan-catatan.

\section{Sumber berupa arsip:}

1) Ihtisar Sidang Pleno II tahun 1958 tentang Bendera, Lagu Kebangsaan, Lambang Negara dan Ibukota.

2) Penetapan Presiden No. 28 tahun 1948 tentang Pembentukan Panitia Indonesia Raya.

3) Naskah Susunan Acara Peringatan Tri-Windhu Lagu Kebangsaan Indonesia Raya.

4) Peraturan Pemerintah No.44 tahun 1958 tentang Lagu Kebangsaan Indonesia Raya

5) Undang-Undang No. 24 tahun 2009 tentang Bendera, Bahasa dan Lambang Negara Serta Lagu Kebangsaan.

6) Surat kabar Sin Po edisi 10 November 1928.

7) Surat Kabar Asia Raya edisi 18 Agustus 1945. 


\section{Kritik}

Setelah sumber-sumber sejarah yang dibutuhkan dalam penulisan proposal penelitian telah terkumpul. Maka penulis melakukan pengujian secara kritis terhadap sumber-sumber sejarah. Hal tersebut bertujuan untuk memperoleh otensitas dan kredibilitas. Kritik sejarah merupakan sebuah metode tafsir yang mempertimbangkan faktor historis dari suau teks untuk menggali makna secara lebih mendalam. Dalam kritik sejarah ini, terdapat dua tahap yaitu tahap kritik ektern atau eksternal dan tahap kritik intern atau internal.

\section{Sumber primer:}

1) Ihtisar Sidang Pleno II tahun 1958 tentang Bendera, Lagu Kebangsaan, Lambang Negara dan Ibukota. Ihtisar ini dikeluarkan pada 6 Oktober 1958 oleh Sekretariat Konstituante Republik Indonesia Seksi Dossier sebagai dokumentasi ihtisar atau kesimpulan Sidang Pleno II tahun 1958. Ihtisar ini berisikan tentang kesimpulan atau hasil Sidang Pleno II tahnu 1958 serta ejaan yang digunakan ialah Ejaan Pembaharuan Pembaharuan dimana masih menggunakan huruf "j" sebagai bunyi huruf " $y$ ". Ihtisar ini merupakan dokumen yang asli bukan turunan, sehingga penulis mengkategorikan ke dalam sumber primer.

2) Penetapan Presiden No. 28 tahun 1948 tentang Pembentukan Panitia Indonesia Raya. Surat ini dikeluarkan pada 16 November 1948 di Yogyakarta oleh A.C. Pringgodigdo selaku Sekretaris Negara sebagai surat perintah pembentukan panitia lagu Indonesia Raya. Surat ini menggunakan Bahasa Indonesia dengan Ejaan Van Ophuysen dimana masih menggunakan gabungan huruf " j" sebagai bunyi huruf "y". Surat ini merupakan dokumen yang asli bukan turunan, sehingga penulis mengkategorikan ke dalam sumber primer.

3) Naskah Susunan Acara Peringatan Tri-Windhu Lagu Kebangsaan Indonesia Raya. Naskah ini dikeluarkan pada 28 Oktober 1952 oleh Panitia Peringatan Tri-Windhu Lagu Kebangsaan Indonesia Raya sebagai rundown atau susunan acara acara peringatan tersebut. Naskah ini menggunakan Bahasa Indonesia dengan Ejaan Van Ophuysen dimana masih menggunakan gabungan huruf "tj" sebagai bunyi huruf "c". Surat ini merupakan dokumen yang asli bukan turunan, sehingga penulis mengkategorikan ke dalam sumber primer. 
4) Peraturan Pemerintah No.44 tahun 1958 tentang Lagu Kebangsaan Indonesia Raya. Peraturan ini dikeluarkan pada 26 Juni 1958 di Jakarta oleh Perdana Menteri Djuanda dan Ir. Soekarno sebagai Presiden Republik Indonesia dengan nama Peraturan Pemerintah No.44 tahun 1958 tentang Lagu Kebangsaan Indonesia Raya sebagai undang-undang lanjutan atas pasal 3 ayat 2 Undang-Undang Dasar Sementara Republik Indonesia. Bahasa yang digunakan dalam Peraturan Pemerintah ini yaitu Bahasa Indonesia dengan Ejaan Pembaharuan Pembaharuan dimana masih menggunakan huruf "j" sebagai bunyi huruf "y". Peraturan Pemerintah ini merupakan dokumen yang asli bukan turunan, sehingga penulis mengkategorikan ke dalam sumber primer.

5) Undang-Undang No. 24 tahun 2009 tentang Bendera, Bahasa dan Lambang Negara Serta Lagu Kebangsaan. Undang-Undang ini dikeluarkan pada 9 Juli 2009 dan disahkan di Jakarta oleh Dr.H. Susilo Bambang Yudhoyono sebagai Presiden Republik Indonesia serta diundangkan pada 9 Juli 2009 di jakarta oleh Andi Mattalatta sebagai Menteri Hukum dan Hak Asasi Manusia Republik Indonesia sebagai Undang-Undang Dasar No. 24 tahun 2009 tentang Bendera, Bahasa dan Lambang Negara Serta Lagu Kebangsaan. Bahasa yang digunakan di dalam Undang-Undang ini yaitu Bahasa Indonesia dengan Ejaan yang disempurnakan. Undang-Undang Dasar ini merupakan dokumen yang asli bukan turunan, sehingga penulis mengkategorikan ke dalam sumber primer.

6) Surat kabar Sin Po edisi 10 November 1928. Surat kabar tersebut memuat beberapa kategori diataranya tentang nasionalisme dengan sub tema Indonesia Raya. Surat kabar ini merupakan dokumen yang asli bukan turunan, sehingga penulis mengkategorikan dokumen tersebut ke dalam sumber primer.

7) Surat Kabar Asia Raya edisi 18 Agustus 1945. Surat kabar ini memuat beberapa kategori diantaranya mengenai peperangan yang terjadi di Jepang dengan Sekutu dan sub tema Indonesia Raya. Surat kabar ini merupakan dokumen yang asli bukan turunan, sehingga penulis mengkategorikan dokumen tersebut ke dalam sumber primer.

\section{Interpretasi}

Interpretasi atau penafsiran sejarah sering disebut dengan analisis sejarah. Analisis berarti menguraikan, dan secara terminologi berbeda 
sintesis yang berarti menyatukan ${ }^{4}$. Analisis dan sintesis dipandang sebagai metode utama dalam interpretasi ${ }^{5}$. Tahap Penafsiran, menafsirkan data-data yang telah dicari, dan dikritik. Lagu Indonesia Raya merupakan sebuah tanda yang memiliki makna yang mendalam bagi masyarakat pada jaman penjajahan. Hal tersebut dapat dilihat dari pengaruh lagu tersebut dalam membangun nasionalisme masyarakat. Berkat karya yang ditulis oleh W.R. Supratman mengandung makna yang mendalam guna membangun rasa nasionalis diantara masyarakat. Makna nasionalis dapat terlihat dengan jelas pada setiap penggalan kata yang terdapat di dalam syair lagu Indonesia Raya. Meski W.R. Supratman hanya seorang jurnalis pada awalnya, namun sifat nasionalis yang dimilikinya begitu besar dan kuat. Sehingga terciptalah lagu Indonesia Raya sebagai representasi nasionalis W.R. Supratman.

\section{Historiografi}

Tahapan historiografi adalah tahapan akhir berupa tulisan yang disusun berdasarkan atas data-data atau sumber yang berhasil mengalami proses kritik serta di interprertasikan baik berupa informasi lisan, tulisan, dan informasi lainnya agar dapat muncul ke permukaan serta sesuai dengan fakta yang ada.

\section{Hasil dan Pembahasan}

\section{A. Lagu Indonesia Raya tahun 1928}

Wage Rudolf Supratman ingin mempersembahkan sesuatu bagu perjuangan. Akan tetapi ia kebingungan bagaimana cara untuk melakukannya. Supratman hanya seorang wartawan dan pemain musik. Secara kebetulan ia membaca majalah Timboel yang terbit di Solo. Dalam majalah tersebut terdapat sebuah sayembara tentang sebuah pertanyaan kepada masyarakat luas mengenai apakah ada komponis Indonesia yang bisa menciptakan lagu kebangsaan untuk menyatukan seluruh masyarakat Indonesia. Ia dengan senang hati mengabarkan kepada Oerip tentang keinginannya menciptakan sebuah lagu untuk Bangsa Indonesia ${ }^{6}$.

Hatinya mulai tergerak setalah membaca tulisan itu. ia merasa bahwa tulisan itu seakan-akan dijukan kepadanya dirinya. Jiwanya semakin gelisah.

\footnotetext{
${ }^{4}$ Sulasman, Metodologi Penelitian Sejarah (Bandung: Pustaka Setia, 2014), 111.

${ }^{5}$ Kuntowijoyo, Metodologi Sejarah, Kedua (Yogyakarta: Tiara Wacana Media, 2003), 100.

${ }^{6}$ Anthony Hutabarat, Wage Rudolf Soepratman (Jakarta: PT BPK Gunung Mulia, 2001), 14 .
} 
Ia sering menyendiri di tempat yang sepi atau mengurung diri di kamarnya yang terletak di Gang Tengah Salemba (Struiswijkstraat) ${ }^{7}$.

Pada suatau malam, ia mengambil beberapa lembar kertas. Tangannya bergetar ketika hendak memulai menuliskan not sebuah lagu. Setelah selesai menuliskan not-not, ia mengambil biolanya untuk memainkan sebuah lagu yang telah ia ciptakan. Namun, lagu tersebut masih dinilai kurang memadai. Ia terus menerus mencoba memperbaiki lagu ciptaannya. Setelah ia merasa puas dengan hasil not lagu itu, ia menulis syair lagu tersebut. Kata-kata yang sudah lama dikandung dalam pikirannya, akhirnya meluncur dari penanya.

Syair lagu itu terasa sangat hidup dan sesuai dengan keadaan Indonesia yang sedang dijajah oleh Kolonial Belanda. Ia merasa batinnya sangat lapang setelah menyelesaikan secara keseluruhan.

Wage Rudolf Supratman mengabadikan lagu perjuangan tersebut ke dalam sebuah piringan hitam. Usaha tersebut dilakukan bersama dengan sahabatnya, Yo Kim Tjan, setelah Wage Rudolf Supratman tidak dapat menghubungi perusahaan His Master Voice di Inggris. Kim Tjan kemudian membeli alat-alat rekaman. Supratman kemudian memainkan biola sambil menyanyikan lagu Indonesia Raya. Selama proses tersebut Kim Tjan bertindak sebagai operator rekaman. Supratman memainkan lagu Indonesia Raya dengan dua irama, yaitu keroncong dan $\operatorname{mars}^{8}$.

Pada 12 Agustus 1928, Panitia Kongres Pemuda Kedua terbentuk. Panitia Kongres menghimbau kepada semua pihak untuk memberikan bantuan. Tidak terkecuali dengan Supratman, yang berniat untuk menyumbangkan sebuah lagu. Ia segera mengirimkan sebuah surat kepada Panitia Kongres Pemuda Kedua dengan harapan ia diperbolehkan untuk memperkenalkan lagu tersebut di depan peserta kongres. Panitia menyetujui permintaan tersebut dan ia diminta untuk melatih paduan suara yang terdiri atas anggota PPPI (Perhimpunan Pelajar Pelajar Indonesia). Pada malam penutupan kongres, Wagu Rudolf Supratman dengan gesekan biolanya mengirigi barisan panduan suara yang membawakan lagu Indonesia Raya. Lagu yang awalnya diberi judul "Indonesia". Namun, dalam

${ }^{7}$ Dkk Rahman, Momon Abdul, Wage Rudolf Supratman Sang Pencipta Lagu Kebangsaan Indonesia Raya (Jakarta: Departemen Kebudayaan Dan Pariwisata Museum Sumpah Pemuda, 2007), 22.

${ }^{8}$ Rahman, Momon Abdul, 23. 
perkembangannya kata "Raya" mulai disematkan pada judul lagu tersebut pada bulan November $1928^{9}$.

Setelah kongres tersebut selesai para Wartawan Indonesia menyiarkan naskah Lagu Indonesia ke seluruh Nusantara dengan cara memuat naskah tersebut ke dalam surat kabar dan majalah. Pada 10 November 1928 W.R. Supratman memuat naskah lagu tersebut ke dalam surat kabar Sin Po, tempat ia bekerja. Surat kabar "Suluh Rakyat Indonesia" juga memuat naskah lagu tersebut disusul dengan berbagai surat kabar dan majalah di jakarta, Bandung, Surabaya, Semarang. Ia juga berperan menyebarluaskan lagunya dengan melatih para pelajar, serta membagikan selebaran pamflet lagu ke masyarakat ${ }^{10}$. Sejak saat itulah Lagu Indonesia sangat cepat dikenal oleh masyarakat luas.

Para pemimpin pergerakan kebangsaan, pemuda dan kepanduan serta tokoh-tokoh pendidikan memiliki andil yang sangat besar dalam menyebarluaskan lagu tersebut. Mereka menganjurkan agar lagu tersebut dipelajari untuk diperdengarkan dan dinyanyikan, baik di dalam gedunggedung pertemuan, sekolah-sekolah dan di lapangan terbuka. Lagu tersebut diperdengarkan dengan penuh semangat, maka tidak mengherankan dalam waktu yang relatif singkat Lagu Indonesia Raya menjadi lagu yang disukai dan sering dinyanyikan bersama-sama. Lagu Indonesia Raya juga menjadi lagu kesayangan sebagian besar masyarakat Indonesia pada saat itu. Hal tersebut dikarenakan isi syair lagu Indonesia Raya sangat menyentuh hati nurani yang mampu menggelorakan semangat persatuan dan rasa kebangsaan $^{11}$.

\section{B. Lagu Indonesia Raya tahun 1945}

Lagu Indonesia Raya pada awal diciptakan oleh Wage Rudolf Supratman berjudul "Indonesia". Sedangkan kata "Raya" menjadi pendamping kata "Indonesia" ketika ia menerbitkan lagu tersebut pada bulan November $1928^{12}$. Kongres PNI Kedua yang telah mengakui Lagu Indonesia Raya menjadi Lagu Kebangsaan Indonesia rupanya memberikan dampak yang besar. Dalam waktu yang sangat singkat organisasi pemuda, organisasi

\footnotetext{
${ }^{9}$ Rahman, Momon Abdul, 23.

${ }^{10}$ W Mintargo, Musik Revolusi Indonesia (Yogyakarta: Penerbit Ombak, 2008), 30.

${ }^{11}$ Bambang Sularto, Sejarah Lagu Kebangsaan Indonesia Raya (Jakarta: Balai Pustaka, 2007), 23.

12 Rahman, Momon Abdul, Wage Rudolf Supratman Sang Pencipta Lagu Kebangsaan Indonesia Raya, 24.
} 
politik, organisasi kepanduan dan masyarakat umum mengakui lagu tersebut sebagai Lagu Kebangsaan Indonesia. Lagu Kebangsaan tersebut diperdengarkan dan dinyanyikan sebelum pertemuan-pertemuan dimulai ${ }^{13}$. Hadirin yang berada dalam pertemuan tersebut harus berdiri untuk menghormatinya ${ }^{14}$. Pada Kongres PNI yang kedua, Lagu Indonesia Raya dibawakan dengan iringan band lengkap.

Kongres ini juga menjadikan lagu tersebut sebagai primadona highlite pada surat kabar. Sehingga permintaan masyarakat terhadap lagu tersebut terus meningkat. Supratman dihubungi oleh sebuah agensi percetakan piringan hitam berdarah Tionghoa, Agensi Tio Tek Hong ${ }^{15}$. Supratman juga memiliki hak-hak eksekutif di Perusahaan Tionghoa yang beroperasi di Batavia. Piringan hitam yang dibuat oleh NV Kuchenmeister's Internationale Ultraphoon Maatschappij Amsterdam yang dibuat pada tanggal 30 Oktober 1930 dengan judul "Indonesia Rajah"16.

Percetakan piringan hitam akan semakin mempermudah penyebaran lagu tersebut. Piringan hitam tersebut sangat laris di pasaran. Namun, sebagian piringan hitam yang belum terjual disita oleh Polisi Belanda. Sebelumnya polisi telah melakukan pemantauan yang cukup panjang mengenai lagu ini ${ }^{17}$. Lagu ini pada zaman Belanda dianggap mengganggu ketertiban umum sehingga Pemerintah Belanda melarang menyanyikan Lagu Indonesia Raya di depan umum pada tahun 1930. Wage Rudolf Supratman diinterogasi oleh PID dan ditanya mengenai motif dari lagu tersebut ${ }^{18}$.

Protes atas larangan menyanyikan Lagu Indonesia Raya datang dari berbagai pihak. Volksraad memiliki andil yang cukup besar dalam protes tersebut. Sehingga Pemerintah Belanda mulai melunakkan larangan tersebut. Akhirnya, Lagu Indonesia Raya boleh dinyanyikan di ruangan tertutup saja $^{19}$. Pemerintah Jepang mengeluarkan serta menetapkan sebuah undang-

\footnotetext{
13 "No Title," Algeemen Handelsblad, 1938.

${ }^{14}$ Sularto, Sejarah Lagu Kebangsaan Indonesia Raya, 165.

15 "No Title," De Sumatra Post, 1932.

16 Rahman, Momon Abdul, Wage Rudolf Supratman Sang Pencipta Lagu Kebangsaan Indonesia Raya, 24.

17 "No Title," Het Nieuws Van Den Dag Voor Nederlandsch-Indie, November 11, 1934.

18 "No Title," Het Nieuws Van Den Dag Voor Nederlandsch-Indie, April 24, 1934.

19 Rahman, Momon Abdul, Wage Rudolf Supratman Sang Pencipta Lagu Kebangsaan Indonesia Raya, 24.
} 
undang sekaligus sebagai pelarangan terhadap Lagu Indonesia Raya telah dideklarasikan oleh Pemerintah Jepang.

Pada tahun 1944 Panitia Lagu Kebangsaan telah dibentuk oleh para pemimpin bangsa. Setelah panitia dibentuk, dilakukan kegiatan untuk menetapkan susunan Lagu Kebangsaan. Lagu Indonesia Raya tetap dipilih oleh panitia sebagai Lagu Kebangsaan. Panitia juga melakukan beberapa perubahan dalam sendi lagu dan kata-kata syair lagu tersebut. Sendi Lagu Indonesia Raya pada awalnya 6/8 dieubah menjadi 4/4. Selain perubahan telah dilakukan oleh panitia, mereka juga tetap mempertahankan keaslian lagu tersebut.

Panitia yang diketuai oleh Ir. Sukarno yang beranggotakan Ki Hadjar Dewantara, Achyar, Bintang Sudibyo, Darma Wijaya, Kusbini, K.H. Mansyur, Mr. Muhammad Yamin, Mr. Sastro Moelyono, Sanusi Pane, Cornel Simandjuntak, Mr. Achmad Soebardjo, dan Utoyo mengadakan beberapa perubahan atas naskah asli Wage Rudolf Supratman. Setelah disahkan tahun 1944, lagu berkumandang dalam rapat pertemuan dan upacara tertentu. Perubahan cukup besar terjadi pada refrain Lagu Indonesia Raya tahun 1928:

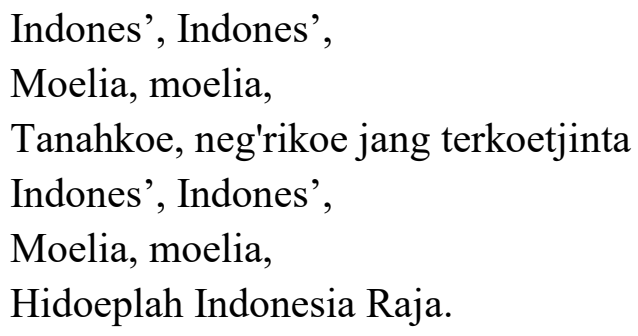

Diubah menjadi:

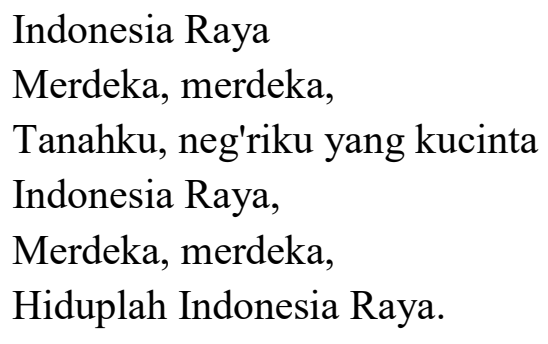

Dalam mengubah sebuah lagu perjuangan menjadi sebuah lagu kebangsaan yang berguna untuk dapat mempersatukan bangsa. Indonesia Raya menjelma sebagai sebuah lagu yang berhasil mempersatukan bangsa. 
Para Pemimpin Indonesia membentuk Panitia Persiapan Kemerdekaan Indonesia (PPKI) pada pertengahan bulan Agustus 1945. Panitia tersebut diketuai oleh Ir. Sukarno dan Drs. Muhammad Hatta. Setelah Indonesia Raya diresmikan sebagai Lagu Kebangsaan Indonesia, masyarakat luas mulai berani menyanyikan Indonesia Raya secara terang-terangan. Dalam waktu singkat lagu tersebut kembali bergema di seluruh Nusantara. Hal tersebut menandakan Indonesia telah siap untuk merebut kemerdekaannya.

\section{Lagu Indonesia Raya tahun 1958}

Kesungguhan pemerintah untuk menggapai keinganan tersebut semakin terlihat jelas. Lagu Indonesia Raya juga menjadi sebuah kebanggaan bagi masyarakat, karena itu banyak masyarakat yang memperdengarkan lagu tersebut di dalam acaranya. Salah satunya di acara pernikahan. Melihat hal tersebut, pemerintah mulai memikirkan sekaligus memperlihatkan kesungguhannya terhadap lagu tersebut.

Pada 16 November 1948 Pemerintah Indonesia mengeluarkan Penetapan Presiden 1948 No. 28 tentang Panitia Indonesia Raya. Pembentukan Panitia Indonesia Raya. Peraturan tersebut di keluarkan oleh Soekarno sebagai Presiden Republik Indonesia. Peraturan tersebut sebagai bentuk untuk mengatur Lagu Indonesia Raya. Pada tanggal 19 Desember 1948 usaha diplomasi pemimpin pergerakan melalui markas PBB di New York ${ }^{20}$ ditetapkan bahwa lagu kebangsaan yang diperjuangkan oleh bangsa Indonesia dicantumkan dalam negara RIS UUDS pasal 3 ayat 2 yang berbunyi bahwa lagu kebangsaan Indonesia ialah Indonesia Raya ${ }^{21}$.

Kedua produk hukum tersebut merupakan cara pemerintah untuk meninggikan derajat Indonesia Raya sebagai Lagu Kebangsaan pada tahun 1948. Begitu juga pada tahun-tahun dimana Indonesia kembali diserang oleh Tentara Belanda di Yogyakarta sebagai Ibu kota negara pada tahun 1948.

Surat Kabar Merdeka memuat laporan tentang Lagu Indonesia Raya dinyanyikan dalam bahasa asing. Lagu tersebut dinyanyikan dalam Bahasa Arab pada acara resmi pembukaan sekolah di Semarang. Lagu tersebut diterjemahkan oleh Muchdori ${ }^{22}$. Pemerintah melarang penggunaan Lagu Indonesia Raya dalam bahasa asing. tentunya ini merupakan salah satu pertimbangan bagi Panitia Lagu Kebangsaan.

20 “Algemeen Dagblad," Het Nieuws Van Den Dag Voor Nederlandsch-Indie, 1948.

${ }^{21}$ Sularto, Sejarah Lagu Kebangsaan Indonesia Raya, 237.

22 "No Title," Nieuwes Courant, 1950. 
Pada bulan Oktober 1952 pemerintah mulai memperingati hari jadi Indonesia Raya ke-24. Pemerintah yang diwakili oleh Kementrian Pendidikan Pengajaran dan Kebudayaan Republik Indonesia mulai mempersiapkannya. Direktur Kabinet Presiden yang diwakili oleh Mr. A. K. Pringgodigdo mengajukan Mr. Hadi sebagai Ketua Acara peringatan tersebut kepada Menteri Pendidikan Pengajaran dan Kebudayaan Republik Indnoesia.

Setelah melalui persiapan yang sangat matang akhirnya susunan acara peringatan 24 tahun Indonesia Raya telah dirancang dengan apik oleh panitia. Acara peringatan tersebut dimulai pukul 19.00- 21.00 WIB yang bertepat di Istana Negara ${ }^{23}$. Sekitar 2.500 tamu undangan, termasuk menteri, warga sipil senior dan warga sipil perwira militer, anggota parlemen, orangorang terkemuka dan siswa memiliki 28 Oktober bersama dengan presiden dan wakil presiden kelahiran orang Indonesia lagu kebangsaan, Indonesia Raya, di Indonesia istana presiden diperingati ${ }^{24}$. Selama upacara ini, Menteri Pendidikan, Pendidikan dan budaya, Dr. Bahder Djohan, dan presiden Sukarno. Setelah presiden dan wakil presiden telah memasuki Istana Negara, dengan yang hadir berdiri, itu menjadi Indonesia Raya memainkan korps kepolisian $^{25}$.

Dalam acara tersebut Menteri Bahder kemudian ingat Kenyataan Djohan, bahwa almarhum W. R. Supratman adalah Indonesia Raya dalam hal itu telah memperkenalkan Kongres 1928 dan bernyanyi di sana sendiri. Lebih lanjut, menteri mengatakan bahwa bekas rezim kolonial bernyanyi Indonesia Raya di sekolah-sekolah dan lainnya peluang, sejak dia mengenali seberapa besar pengaruh lagu itu memicu dorongan untuk kebebasan. Peringatan terakhir, Menteri Bahder Djohan, meskipun Indonesia sekarang menjadi kemandirian politik telah mencapai, pertarungan belum berakhir dan harus dilanjutkan bidang ekonomi dan budaya ${ }^{26}$.

Acara tersebut memuat arti yang sangat penting Indonesia Raya untuk seluruh masyarakat. Maka tidaklah heran lagu ini memiliki kedudukan yang sangat tinggi serta dihormati. Acara peringatan tersebut didedikasikan pada Indonesia Raya, khususnya W.R. Supratman sebagai pencipta sebagai apresiasi pemerintah. Indonesia Raya merupakan satu dari sekian banyaknya

${ }^{23}$ Rencana Tri-Windhu Lagu Kebangsaan Indonesia Raya. 28 Oktober 1952.

24 "No Title," Java Bode: Nieuws Handels- En Advertintieblad Voor NederlandschIndie, 1952.

25 "No Title," NIEUWSGIER, 1952.

26 "No Title," 1952. 
sarana yang digunakan untuk memperoleh persatuan dan kesatuan ${ }^{27}$. Perjuangan bangsa Indonesia pada awalnya masih bersifat kedaerahan, seperti Jong Java dan sebagainya. Dengan adanya Kongres Pemuda Kedua pada 28 Oktober 1928 merupakan sebuah jalan bagi Lagu Indonesia Raya untuk muncul sebagai salah satu sarana pemersatu bangsa, melalui W.R. Supratman.

Cikal bakal rasa nasionalisme dalam syair Indonesia Raya telah berakar pada masyarakat Indonesia. Inilah nilai-nilai yang tersirat secara tersurat oleh W.R. Supratman untuk dapat menyadarkan masyarakat guna tetap mencintai dan membela bangsanya. Memperingati 25 tahun yang lalu Lagu Kebangsaan Indonesia Raya untuk pertama kalinya dimainkan. Fakta ditemukan tempat pada 28 Oktober 1928, lalu Wage Rudolf Supratman di Kongres Pemuda Indonesia di Batavia lagu dinyanyikan. Lagu itu sangat istimewa semoga sukses karena melodi mudah didengar. Oleh perasaan nasional khusus, itu selain itu, liriknya diungkapkan, lagu itu segera berkembang menjadi simbol keinginan untuk kebebasan. Indonesia Raya sebagai lagu kebangsaan Indonesia telah berkembang ke dalamnya simbol untuk persatuan dan ideal dari negara kesatuan 28. Pemerintah memberlakukan sebuah Peraturan Pemerintah Tentang Lagu Kebangsaan Indonesia Raya. Hal tersebut berguna untuk mencapai keseragaman dalam penggunaannya dan merupakan suatu lambang negara yang harus dihormati setinggi-tingginya oleh seluruh lapisan masyarakat Indonesia.

Lagu Indonesia Raya tahun 2009

Pemerintah mengeluarkan Peraturan No. 44 Tahun 1958 tentang Lagu Kebangsaan Indonesia Raya ${ }^{29}$. Dimana pemerintah telah menimbang Lagu Indonesia Raya sebagai Lagu Kebangsaan Republik Indonesia. Hal tersebut dikarenakan lagu tersebut telah dikenal dan diketahui oleh masyarakat umum. Peraturan tersebut juga berguna untuk mencapai keseragaman, sehingga ditetapkan juga nada-nada, irama, iringan, kata-kata dan gubahan lagu tersebut. Serta waktu dan acara penggunaannya, baik lagu Indonesia Raya dinyanyikan sendiri maupun bersamaan dengan lagu kebangsaan asing.

27"No Title," 1952.

28 "No Title," Java Bode, 1953.

${ }^{29}$ Peraturan Pemerintah No. 44 Tahun 1958. 
Lagu Indonesia Raya mendapatkan perhatian berkelanjutan dari pemerintah. Hal tersebut terlihat sejak 17 Juli 1957 hingga Agustus 1959 pemerintah bersama Majelis Permusyawaratan Rakyat dan Komisi IV Dewan Perwakilan Rakyat telah membuat daftar rumusan undang-undang tentang lagu Indonesia Raya ${ }^{30}$. Pemerintah mulai membahas perubahan yang dilakukan oleh panitia bersifat seperlunya, dalam hal ini ditekankan kepada melodinya yang disederhanakan agar masyarakat tidak mengalami kesulitan dalam menyanyikannya, syair lagu Indonesia Raya disesuaikan dengan dasar negara, arti lagu Indonesia Raya harus disertai dengan terjemahannya,

Pada 7 Agustus 1958 pemerintah beserta seluruh jajaran dan panitia lagu kebangsaan telah memiliki satu suara untuk menerima Lagu Indonesia Raya sebagai Lagu Kebangsaan, melodi dan syairnya tetap sesuai dengan yang ada. Sehingga pada 9 September 1958 melalui keputusan no. 35/K/1958 pemerintah telah menetapkan Rumusan Undang-undang dasar tentang Lagu Kebangsaan, yatu ayat 1: tentang Lagu Kebangsaan ialah Lagu Indonesia Raya dan ayat 2: pemakaiannya diatur dengan Undang-undang Dasar $^{31}$.

Lagu Indonesia Raya memliki perannya tersendiri, dimana sebelum merdeka lagu tersebut berperan sebagai lagu yang anti kolonial dan menentangnya. Hal tersebut telah sangat jelas dalam kebijakan-kebijakan yang diberlakukan oleh pemerintah kolonial dan Jepang terhadap lagu tersebut. Namun, setelah merdeka lagu tersebut masih memiliki peran sebagai sarana untuk mempersatukan bangsa dan menjaga keutuhan bangsa.

Pada 1990 muncul sebuah lagu perjuangan karya mahasiswa berserta sumpah sumpahnya yang menjadikan lagu Indonesia Raya tergoyangkan posisinya. Lagu tersebut tidak memiliki irama mars seperti lagu Indonesia raya, tetapi memiliki ruang lingkup yang sama yaitu cinta tanah air, dan cinta kealaman Indonesia. Namun, Indonesia masih tetap memiliki posisinya tersendiri. Di samping naiknya lagu perjuangan yang menggoyangkan posisi Indonesia Raya, akan tetapi pada aktualisasinya lagu perjuangan tersebut dinyanyikan setelah pengibaran bendera merah putih yang diiringi oleh lagu Indonesia Raya.

Lagu kebangsaan Indonesia Raya hanya diperdengarkan pada saat tertentu dan peristiwa penting saja dengan cara dan aturan tersendiri.

\footnotetext{
${ }^{30}$ Teks Rumusan Undang-Undang tentang Lagu Kebangsaan tahun 1959.

${ }^{31}$ Teks Rumusan Undang-Undang tentang Lagu Kebangsaan tahun 1959.
} 
Misalnya pada kesempatan-kesempatan dimana lagu kebangsaan diperdengarkan dengan alat musik, maka lagu itu dibunyikan lengkap satu kali, yaitu strofe dengan dua kali ulangan. Jika pada kesempatankesempatan lagu kebangsaan dinyanyikan lengkap satu bait, yaitu bait pertama dengan ulangan dua kali ${ }^{32}$. Jika lagu kebangsaan dinyanyikan keseluruhan, yaitu tiga bait, maka sesudah bait pertama dan bait yang kedua dinyanyikan ulangan satu kali sesudah bait penghabisan dinyanyikan ulangan dua kali.

Kekuatan lagu Indonesia Raya bukan terletak pada kemampuannya membawa pendengarnya sendirian hanyut ke dalam permenungan yang dalam, meskipun pesan-pesan di baliknya menggali falsafah hidup pencerahan khas Indonesia. Lagu ini harus dinyanyikan bersama-sama dengan banyak suara untuk dapat merasakan kegentingannya. Lagu ini adalah lagu rakyat. Seperti kebanyakan karya seni mutakhir, lagu Indonesia Raya memiliki banyak lapisan untuk didekati. Lagu itu bisa saja digunakan ketika kita sedang santai sembari minum kopi sendiri, misalnya, menandakan interaksi dengan lapisan pertama. Tapi, lagu itu juga bisa membuat kita duduk tafakur memikirkan pesan-pesan intinya. Kesederhanaan yang melekat pada musik Indonesia Raya mampu menjadi kiasan untuk mengundang kontemplasi lebih jauh mengenai tatanan ideal ${ }^{33}$.

Pada tahun 2000 Pemerintah Republik Indonesia melakukan perbaikan untuk menindaklanjuti Peraturan Pemerintah No. 44 Tahun 1958 tentang Lagu Kebangsaan. Pada dasarnya pemerintah masih tetap dipengaruhi oleh Undang-Undang Dasar Sementara Tahun 1950. Dalam undang-undang tersebut membahas mengenai Bendera, Bahasa, dan Lambang Negara, serta Lagu Kebangsaan ${ }^{34}$. Pemerintah Republik Indonesia melalui presiden mengeluarkan undang-undang pada tahun 2004. Lagu Kebangsaan Indonesia Raya memiliki kedudukan tertinggi dalam sepanjang karirnya. Pasal 36 merupakan produk hukum yang menaungi Lagu Indonesia raya. Sehingga jelaslah Lagu Kebangsaan Indonesia Raya telah menjelma menjadi hal terpenting dari bagian negara.

\footnotetext{
${ }^{32}$ Lokananta, Indonesia Raya (Jakarta: Orkes Studio Jakarta, 1991).

${ }^{33}$ I Gusti Agung Anom Adithyo, Dirdho dan Astika, Bunyi Merdeka Sejarah Sosial Dan Tinjauan Musikologi Lagu Kebangsaan Indonesia Raya (Jakarta: Kementrian Pendidikan dan Kebudayaan Direktorat Jenderal Kebudayaan Direktorat Kesenian, 2017), 100.

${ }^{34}$ Undang-Undang No. 24 tahun 2009 tentang Bendera, Bahasa dan Lambang Negara Serta Lagu Kebangsaan.
} 
Perkembangan Lagu Indonesia Raya (Tahun 1928-2009) | Febriansyah Pratama Putra, Fajriudin, Agus Permana

\section{Kesimpulan}

Perkembangannya lagu Indonesia Raya memiliki sikap konsisten dalam menyampaikan makna yang terdapat di dalamnya secara berlanjut dari sebelum merdeka yaitu 1928 hingga era modern pada tahun 2009. Pertama, pada tahun 1928 lagu Indonesia Raya dapat mempersatukan bangsa. Lirik syair lagu Indonesia Raya mengandung makna besar di dalamnya. Sehingga masyarakat nusantara dapat menerimanya. Kedua, pada tahun 1945 lirik lagu Indonesia Raya mengalami perubahan yang cukup besar, namun Panitia Lagu Kebangsaan Indonesia Raya tetap mempertahankan estetika nilai yang terkandung di dalamnya sebelum dilakukan perubahan. Ketiga, pada tahun 1958 Lagu Indonesia Raya mendapatkan perhatian yang besar dari pemerintah. Kedudukannya sebagai Lagu Kebangsaan kembali dipertegas dan diperkokoh dalam Peraturan Pemerintah No. 44 tahun 1958. Keempat, pada tahun 2009 pemerintah kembali menempatkan ulang posisi Lagu Indonesia Raya sebagai Lagu Kebangsaan melalui Undang-undang No. 24 tahun 2009 bersamaan dengan bendera, lambang negara dan bahasa. Dalam undang-undang tersebut telah sangat jelas bahwa Lagu Indonesia Raya tidak mengalami perubahan dalam liriknya yang bertujuan untuk menyesuaikan makna pada era modern ini.

\section{Daftar Sumber}

Adithyo, Dirdho dan Astika, I Gusti Agung Anom. Bunyi Merdeka Sejarah Sosial Dan Tinjauan Musikologi Lagu Kebangsaan Indonesia Raya. Jakarta: Kementrian Pendidikan dan Kebudayaan Direktorat Jenderal Kebudayaan Direktorat Kesenian, 2017.

“Algemeen Dagblad." Het Nieuws Van Den Dag Voor Nederlandsch-Indie, 1948.

Hutabarat, Anthony. Wage Rudolf Soepratman. Jakarta: PT BPK Gunung Mulia, 2001.

Kuntowijoyo. Metodologi Sejarah. Kedua. Yogyakarta: Tiara Wacana Media, 2003.

Lokananta. Indonesia Raya. Jakarta: Orkes Studio Jakarta, 1991.

Mintargo, W. Musik Revolusi Indonesia. Yogyakarta: Penerbit Ombak, 2008.

"No Title." De Sumatra Post, 1932.

"No Title." Het Nieuws Van Den Dag Voor Nederlandsch-Indie, April 24, 
Perkembangan Lagu Indonesia Raya (Tahun 1928-2009) | Febriansyah Pratama Putra, Fajriudin, Agus Permana

1934.

"No Title." Het Nieuws Van Den Dag Voor Nederlandsch-Indie, November $11,1934$.

"No Title." Algeemen Handelsblad, 1938.

"No Title." Nieuwes Courant, 1950.

"No Title." Java Bode: Nieuws Handels- En Advertintieblad Voor Nederlandsch-Indie, 1952.

"No Title." NIEUWSGIER, 1952.

"No Title." Java Bode, 1953.

Rahman, Momon Abdul, Dkk. Wage Rudolf Supratman Sang Pencipta Lagu Kebangsaan Indonesia Raya. Jakarta: Departemen Kebudayaan Dan Pariwisata Museum Sumpah Pemuda, 2007.

Sularto, Bambang. Sejarah Lagu Kebangsaan Indonesia Raya. Jakarta: Balai Pustaka, 2007.

Sulasman. Metodologi Penelitian Sejarah. Bandung: Pustaka Setia, 2014.

Wisnu, Mintargo. "KONTINUITAS DAN PERUBAHAN MAKNA LAGU KEBANGSAAN INDONESIA RAYA.” Kawistara: Jurnal Ilmiah Sosial Dan Humaniora 2, no. 3 (2012). https://jurnal.ugm.ac.id/kawistara/article/view/3942. 
Perkembangan Lagu Indonesia Raya (Tahun 1928-2009) | Febriansyah Pratama Putra, Fajriudin, Agus Permana 